\title{
Cell-Set Modelling for a Microtab Implementation on a DU91W(2)250 Airfoil
}

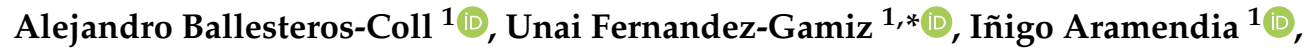 \\ Ekaitz Zulueta ${ }^{2}$ and José Antonio Ramos-Hernanz ${ }^{3}$ iD \\ 1 Department of Nuclear and Fluid Mechanics, University of the Basque Country (UPV/EHU), Nieves Cano \\ 12, 01006 Vitoria-Gasteiz, Spain; aballesteros013@ehu.eus (A.B.-C.); inigo.aramendia@ehu.eus (I.A.) \\ 2 Automatic Control and System Engineering Department, University of the Basque Country UPV/EHU, \\ Nieves Cano 12, 01006 Vitoria-Gasteiz, Spain; ekaitz.zulueta@ehu.eus \\ 3 Electrical Engineering Department, University of the Basque Country (UPV/EHU), Nieves Cano 12, \\ 01006 Vitoria-Gasteiz, Spain; josean.ramos@ehu.eus \\ * Correspondence: unai.fernandez@ehu.eus
}

Received: 2 November 2020; Accepted: 17 December 2020; Published: 20 December 2020

\begin{abstract}
Microtabs (MTs) are a regularly used flow control device in terms of wind turbine optimization. The present study introduces the application of the novel cell-set model for an MT implementation on a DU91W(2)250 airfoil. The cell-set model is based on the reusability of a mesh to add new geometries on the domain; the matching geometry is located where the user requires, and a set of cells is constructed around the mentioned geometry. Subsequently, wall boundaries are assigned to the generated region. Computational simulations were carried out for fully mesh and cell-set models: MT lengths were set at 1.0\%, 1.5\% and 2.0\% of the airfoil chord length (c) and the MTs were placed at $93 \%$ and $95 \%$ of $c$ from the leading edge of the airfoil. Resulting data showed that the MT behavior was similar for both models with regard to aerodynamic performance curve representations. A global relative error of $3.784 \%$ was obtained for the cell-set model and a maximum relative error of $7.332 \%$ was determined. Qualitatively, both models generated significantly similar flow stream velocity wakes on the trailing edge area of the airfoil.
\end{abstract}

Keywords: flow control; wind turbine; microtab; aerodynamics; cell-set model

\section{Introduction}

According to the last report of the International Energy Agency (IEA), environmental impact concerns and future shortages necessitate the generation of electrical energy using non-polluting energy systems. Wind turbine optimization is a noteworthy research field for the industry and scholar researchers.

The optimization of wind turbines is usually carried out throughout numerical simulations. In a study by Howell et al. [1], the aerodynamics of a vertical axis wind turbine (VAWT) were analyzed experimentally and by means of computational fluid dynamics (CFD). Nevertheless, the aerodynamic improvements for horizontal axis wind turbines (HAWTs) proved to be of higher interest in terms of energy production. The wake aerodynamics generated by an HAWT were calculated through CFD numerical simulations in research presented by Vermeer et al. [2].

The implementation of flow control devices on wind turbines proved to be a simple and effective solution for wind turbine optimization. Depending on their principle, these devices can be active or passive [3]. As reported by Aramendia et al. [4], some of the most used flow control devices are vortex generators (VGs), Gurney flaps (GFs) and microtabs (MTs). 
Firstly, VGs are small plates generally located on the suction side of an airfoil, close to the leading edge, and are typically mounted in pairs (see Velte et al. [5] and Godard et al. [6]). A work based on numerical simulations presented by Gao et al. [7] determined that the implementation of VG pairs on a DU97W300 airfoil increased the aerodynamic performance of the airfoil for high angles of attack (AoAs). Then, the results were compared and validated against experimental data from Timmer et al. $[8,9]$. Despite this, for several applications, conventional VGs may not be suitable since a drag overload tends to appear. This issue was presented in research made by Martinez-Filguera et al. [10] and Lin et al. [11] wherein low-profile VGs were purposed as a solution for the boundary layer flow separation when drag overload occurred.

Secondly, GFs are L-shaped fixed flaps commonly positioned on the trailing edge of an airfoil and perpendicularly directed from the pressure side [12]. Based on wind tunnel results for nine airfoils and different GF lengths, Alber et al. [13] reported that the aerodynamic performance of an airfoil was enhanced when short GF lengths were considered. Furthermore, numerical CFD simulations of GF implementations carried out by Aramendia et al. [14] described that the application of a GF produced a lift enhancement at low AoAs. However, research on adaptive flaps results to be attractive since the flap can be orientated to reach suitable performances at different angles of attack. According to Zhu et al. [15], who carried out two-dimensional simulations of active GFs implemented on energy-harvesting wing foils, an adaptive GF provides greater energy-harvesting efficiency by increasing the heave force through synchronous switching of the flap. In the study of Saenz-Aguirre et al. [16], an optimal wind turbine operation was designed by an artificial neural network (ANN) using active GFs.

Thirdly, the implementation of MTs is the principal point of the present work. MTs are short plates typically located near to the trailing edge of an airfoil and perpendicularly projected to the pressure side. The possibilities and capabilities of MTs were firstly introduced by Gruschwitz and Schrenk (1993) [17] and further investigated by van Dam et al. [18] and Baker et al. (2007) [19]. In their studies, the tabs were implemented onto a 5809 baseline airfoil. An MT application provides a lift enhancement by changing the flow separation point. Nevertheless, when the MT is located on the suction side and points upwards, the lift coefficient $\left(\mathrm{C}_{\mathrm{L}}\right)$ is decreased. In a work carried out by Ebrahimi and Movahhedi [20], the implementation of an MT positioned at $95 \%$ of the chord length of an NREL (National Renewable Energy Laboratory) Phase VI upwind turbine airfoil section saved a maximum of $17 \%$ of wasted energy. Cooperman et al. [21] performed two-dimensional numerical simulations of active MT load control and the results obtained turned out to be close to experimental wind tunnel data. Additionally, a study by Johnson et al. [22] presents an outline of active load control techniques for wind turbines, emphasizing on MT control.

An essential point of this study is the application of alternative models and methods for the modeling of flow control devices in order to reduce computational costs and meshing time. Up to now, several different CFD techniques have been employed for flow control device modeling (see Sanderse et al. [23]). Notwithstanding, a novel method has been used for the numerical simulations of this study. This new method is named after the cell-set model and was firstly presented in Ballesteros-Coll et al. [24]. In essence, this model reuses the cells of an already generated mesh to generate new geometries. A deeper description of this model is presented in the following section. Similar models, such as the jBAY model introduced in Jirasek [25], have been broadly investigated by Errasti et al. [26], Chillon et al. [27] and Fernandez-Gamiz et al. [28]. Additionally, methods such as the proper orthogonal decomposition (POD) method presented in Fernandez-Gamiz et al. [29] considerably reduce the computational cost of the simulations.

The main goal of the current work is the analysis of the cell-set model performance for the implementation of a microtab (MT) on a DU91W(2)250 aerodynamic profile. The DU91W(2)250 airfoil is a widely referenced profile in the wind manufacturing industry and introduced in the NREL $5 \mathrm{MW}$ referenced wind turbine [30]. On the other hand, the cell-set model provides flexibility and manageability when the addition of new geometries is required. The model leverages the cells where the geometry would be located and generates a new wall region on those cells, resulting in an alternative 
to save computational and meshing costs. In order to study the performance of the cell-set model, the results have been compared with the ones obtained from a completely meshed computational domain, denoted as the fully mesh model in the present work. Different MT configurations have been established for a range of AoAs. The results have been represented with the aerodynamic performances of the airfoil $\left(C_{L} / C_{D}\right.$ ratios), and the cell-set performances are defined by means of the relative errors of the lift-to-drag ratio between the cell-set and fully mesh models.

The manuscript is structured as follows: initially, the materials and the methodology used in order to carry out the numerical simulations are presented in Section 2. Subsequently, in Section 3, the resulting data are provided through quantitative and qualitative representations of the results. The last section presents a summary of the main and essential conclusions gathered from the current study.

\section{Materials and Methods}

\subsection{Numerical Setup}

The present study has been based on a numerical analysis for MT implementation on a DU91W(2)250 airfoil. This airfoil is commonly used for horizontal axis wind turbine (HAWT) multi-megawatt applications; see the report of Jonkman et al. [30]. Two different models are presented in this manuscript: the cell-set model and the fully mesh model. In order perform numerical simulations, the STAR CCM+ v14.02.012 [31] commercial CFD software was selected.

The numerical scenarios were based on a DU91W(2)250 airfoil, where a two-dimensional O-mesh was generated around the aerodynamic profile. The radius of the mesh was set at $R=42 \times c$, where $c=$ $1 \mathrm{~m}$ is the airfoil chord length. This radius dimension was set in accordance with the recommendation from a study by Sørensen et al. [32]. As previously mentioned, two different models have been studied for the implementation of different MT configurations on the DU91W(2)250: the cell-set model was based on a clean airfoil grid domain without flow control devices, and all the scenarios for this model were based in that mesh. Conversely, the fully mesh cases needed different scenarios for each MT position and length. The structured grid where the cell-set model was applied was set at 207,740 finite elements. Similarly, for the fully mesh cases, the domain ascended to 232,415 cells, as the implementation of an MT close to the trailing edge area of the airfoil required a mesh refinement. A mesh dependency study on the DU91W(2)250 airfoil performed by Fernandez-Gamiz et al. [33] identified that the dependency of the mesh reached less than $4 \%$ for lift and drag coefficients calculations. Figure 1 illustrates an enlarged view of the clean mesh for the DU91W(2)250 aerodynamic profile. With the purpose of determining the first cell height, a normalization with the airfoil chord length was calculated, which was set at $\Delta \mathrm{z} / \mathrm{c}=1.349 \times 10^{-6}$. The stretching in normal and chord-wise directions was achieved by tanh stretching functions which are based on Thompson et al. [34] and Vinokur [35]. The design of the grid was prepared to obtain dimensionless distances $(y+<1)$ on the surface wall of the airfoil. The maximum skewness angle of the mesh reached $22.99^{\circ}$. The airfoil surface was set as a non-slip wall boundary type.

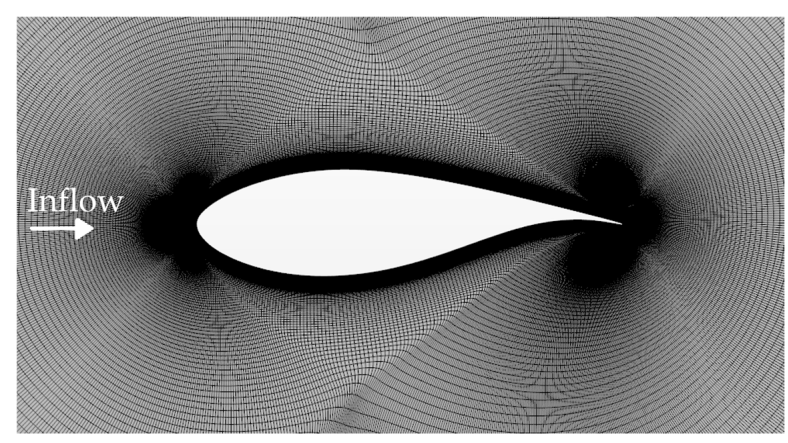

Figure 1. DU91W(2)250 mesh, centered view. The snapshot shows a clean profile without any flow control device implemented. 
The simulations were carried out with a Reynolds number of $\operatorname{Re}=7 \times 10^{6}$, which is based on the airfoil chord length. Furthermore, the equations assigned to the fluid region of the computational domain were based on Reynolds-averaged Navier-Stokes (RANS) equations. Particularly, the shear stress transport (SST) model has been applied to the numerical simulations presented in this manuscript to model turbulence. As identified by Menter [36], the SST model accomplishes the fusion of the standard $k-\varepsilon$ and $k-\omega$ turbulence model by means of a gradual variation on the turbulence properties: close to the surface wall, the calculations are determined relying on $k-\omega$ turbulence, while for the cells which are far from the wall boundary, $\mathrm{k}-\varepsilon$ standard turbulence is applied; see Kral [37]. The upwind algorithm was used for determining the pressure velocity coupling and a linear upwind second-order scheme was employed for the mesh discretization.

The physical properties of the air were established as follows: the air density was set at $\rho=1.204 \mathrm{~kg} / \mathrm{m}^{3}$ and a dynamic viscosity value of $\mu=1.829 \cdot 10^{-5} \mathrm{~Pa} \cdot \mathrm{s}$ was introduced. The relative wind velocity value $V_{\text {rel }}=106.6 \mathrm{~m} / \mathrm{s}$.

The results have been represented by means of aerodynamic performance of the airfoil, also known as the lift-to-drag ratio, which represents the relationship between lift $\left(C_{L}\right)$ and drag $\left(C_{D}\right)$ dimensionless coefficients. Lift and drag coefficients were calculated through Equations (1) and (2), respectively.

$$
\begin{aligned}
& C_{L}=\frac{L}{\frac{1}{2} \rho U_{\infty}^{2} c} \\
& C_{D}=\frac{D}{\frac{1}{2} \rho U_{\infty}{ }^{2} c}
\end{aligned}
$$

\subsection{MT Configurations}

For the numerical simulations, different MT configurations were implemented. Figure 2 illustrates a sketch of the tab setup: $x[\% c]$ represents the MT position on the pressure side of the airfoil (relative position from the leading edge) and $\mathrm{y}[\% \mathrm{c}]$ is the MT length. In particular, the sketch shows a detailed view of an MT construction on a DU91W(2)250 airfoil based on the cell-set model.

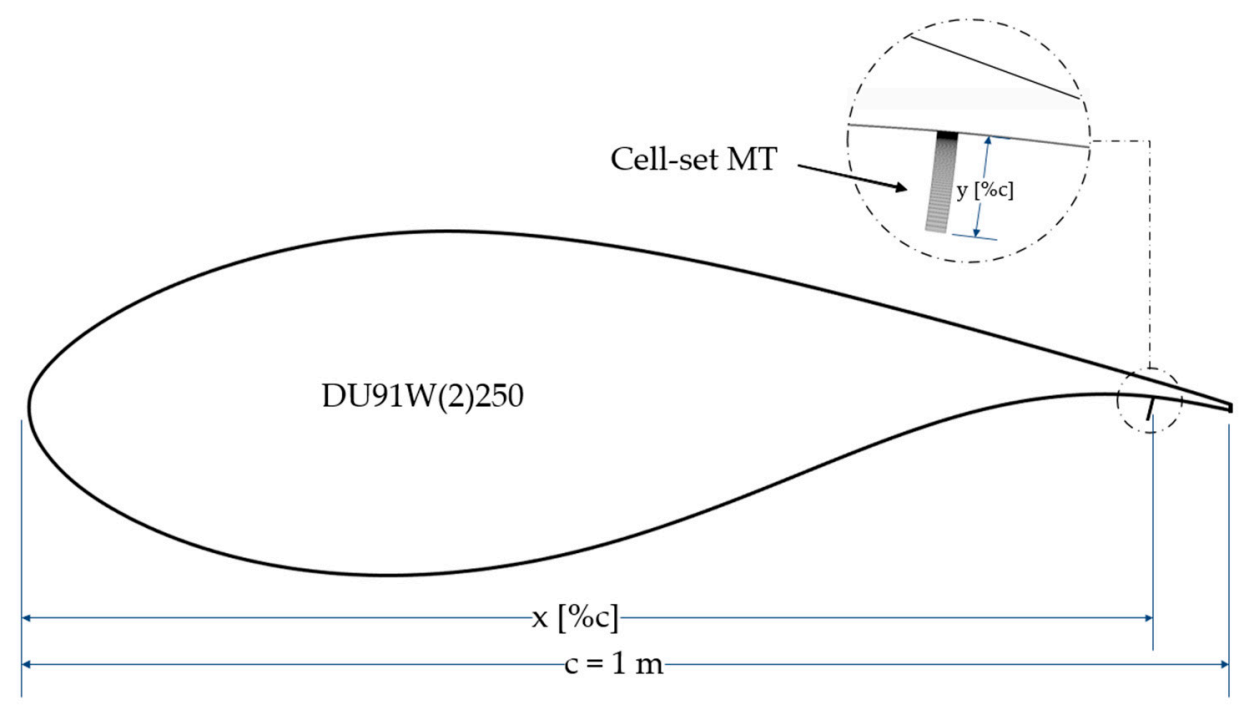

Figure 2. Sketch of the microtab (MT) setup. The relative position and length of the MT are determined by $x[\% c]$ and $y[\% c]$, respectively. The detail view shows an MT cell-set construction for an $\mathrm{x}[\% \mathrm{c}]=$ $93 \%$ and $y[\% c]=1.0 \%$ configuration.

MTs were located at two different positions near to the trailing edge of the airfoil: $x[\% c]=93 \%$ and $x[\% c]=95 \%$. Three different MT lengths were established for the numerical analyses: $y[\% c]=1.0 \%$, 
$y[\% c]=1.5 \%$ and $y[\% c]=2.0 \%$. The angles of attack (AoAs) ranged from 0 to $9^{\circ}$. Firstly, numerical simulations were performed with the fully mesh MTs and then the simulations were repeated by applying the cell-set model. All the cases have been named and classified in Table 1.

Table 1. MT configuration cases.

\begin{tabular}{ccccc}
\hline Case & Short Ref. & $\mathbf{x}[\% \mathbf{c}]$ & $\mathbf{y}[\% \mathbf{c}]$ & Model \\
\hline DU91W(2)250 & clean & no MT & no MT & Fully mesh \\
DU91W(2)250_MTCS9310 & CS9310 & 93 & 1.0 & Cell-set \\
DU91W(2)250_MTCS9315 & CS9315 & 93 & 1.5 & Cell-set \\
DU91W(2)250_MTCS9320 & CS9320 & 93 & 2.0 & Cell-set \\
DU91W(2)250_MTCS9510 & CS9510 & 95 & 1.0 & Cell-set \\
DU91W(2)250_MTCS9515 & CS9515 & 95 & 1.5 & Cell-set \\
DU91W(2)250_MTCS9520 & CS9520 & 95 & 2.0 & Cell-set \\
DU91W(2)250_MTFM9310 & FM9310 & 93 & 1.0 & Fully mesh \\
DU91W(2)250_MTFM9315 & FM9315 & 93 & 1.5 & Fully mesh \\
DU91W(2)250_MTFM9320 & FM9320 & 93 & 2.0 & Fully mesh \\
DU91W(2)250_MTFM9510 & FM9510 & 95 & 1.0 & Fully mesh \\
DU91W(2)250_MTFM9515 & FM9515 & 95 & 1.5 & Fully mesh \\
DU91W(2)250_MTFM9520 & FM9520 & 95 & 2.0 & Fully mesh \\
\hline
\end{tabular}

\subsection{Cell-Set Model}

As previously reported, half of the simulations were based on the novel cell-set model. The verification of the cell-set model for MT implementation is the main point of the present study. This method was firstly used on a study by Ballesteros-Coll et al. [24] where a Gurney flap implementation was carried out. The model resulted to be considerably accurate to be implemented in other scenarios where small flow control devices have to be added on an airfoil. Nevertheless, when arbitrary modifications are required, the immersed boundary method (IBM) is a suitable option (see Reck [38]). For the generation of the cell-set model, firstly, the required geometry is generated onto the mesh, and subsequently, the cells which are around the mentioned geometry are selected by means of their IDs. Once a set of cells (cell set) is created, it is split from the fluid region by generating a new region. After that, a wall boundary limit is assigned to the region that has been built. Thus, this region follows the same equations that have been applied to the fluid region, RANS equations. Consequently, no re-meshing processes are needed in order to generate a new functional geometry. Figure 3 illustrates how small MTs are constructed by using the cell-set model compared to a fully mesh model.
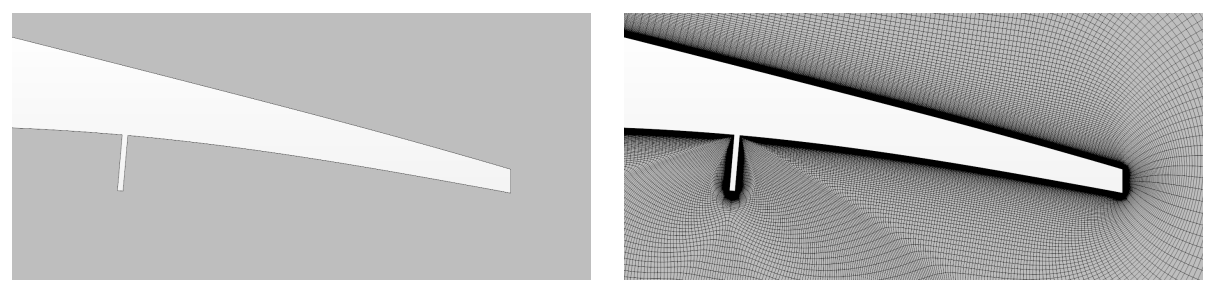

(a)
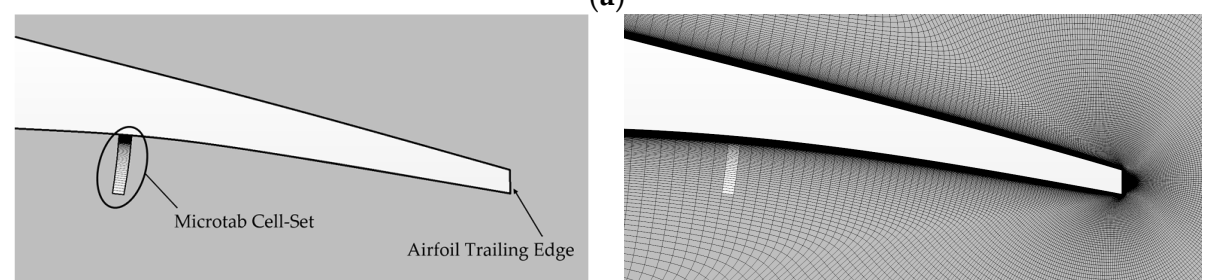

(b)

Figure 3. Comparison of the models for the generation of new geometries (microtabs): (a) fully-mesh model, DU91W(2)250_MTFM9310; (b) cell-set model, DU91W(2)250_MTCS9310. Snapshots show the mesh distribution around trailing edge area of the airfoil. 


\section{Results}

This section presents the results obtained with the cell-set model and the fully mesh model. Firstly, the performance of the model is visualized by means of representing different scenarios for MT implementation. Secondly, the errors of the cell-set model for each case have been determined with the aim of having quantitative results of the model. Additionally, qualitative results have been illustrated as a means to represent the cell-set model against the fully mesh model onto a scalar scene.

\subsection{Cell-Set Model Performance for a Microtab Implementation}

First of all, in order to study the effects of MT implementation for different positions on the pressure side of the airfoil $(x[\% c])$, three plots have been generated; see Figure 4 . Each plot illustrates the relationship between the aerodynamic performance of the airfoil $\left(C_{L} / C_{D}\right.$, lift-to-drag ratio) and the AoA. There are six curves per plot: the continuous black line shows the values reached for the clean case, a DU91W(2)250 airfoil without flow control devices. These values are directly compared and validated against the ones obtained for a X-foil case (red-cross markers) from the DOWEC project which was carried out by Kooijman et al. [39] and Lindenburg [40]. Likewise, the values obtained from both models, cell-set and fully mesh, have been displayed in Figure 4. Red and green curves with asterisk markers show the performance values reached for the cell-set model while the blue and cyan curves with square markers present the performances for the fully mesh model. Two positions on the pressure side of the aerodynamic profile are introduced in each plot: $x=93 \%$ of $c$ and $x=95 \%$ of $c$. In addition, for each device position, three different MT lengths are shown (one per plot) in Figure 4: $y=1.0 \%$ of $c(a), y=1.5 \%$ of $c(b)$ and $y=2.0 \%$ of $c(c)$.

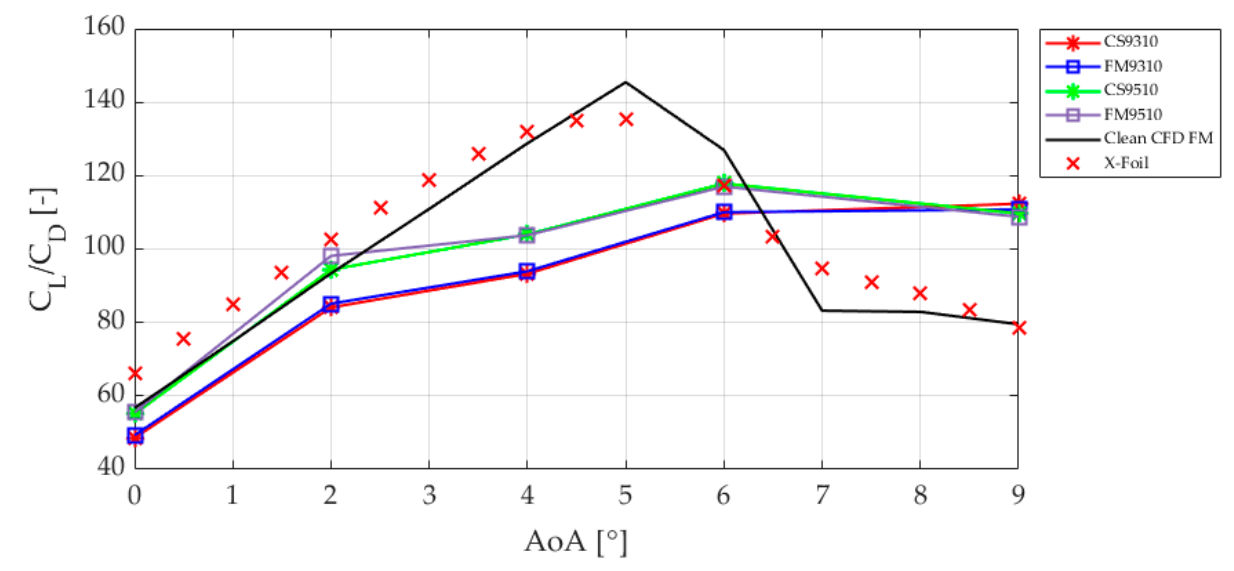

(a)

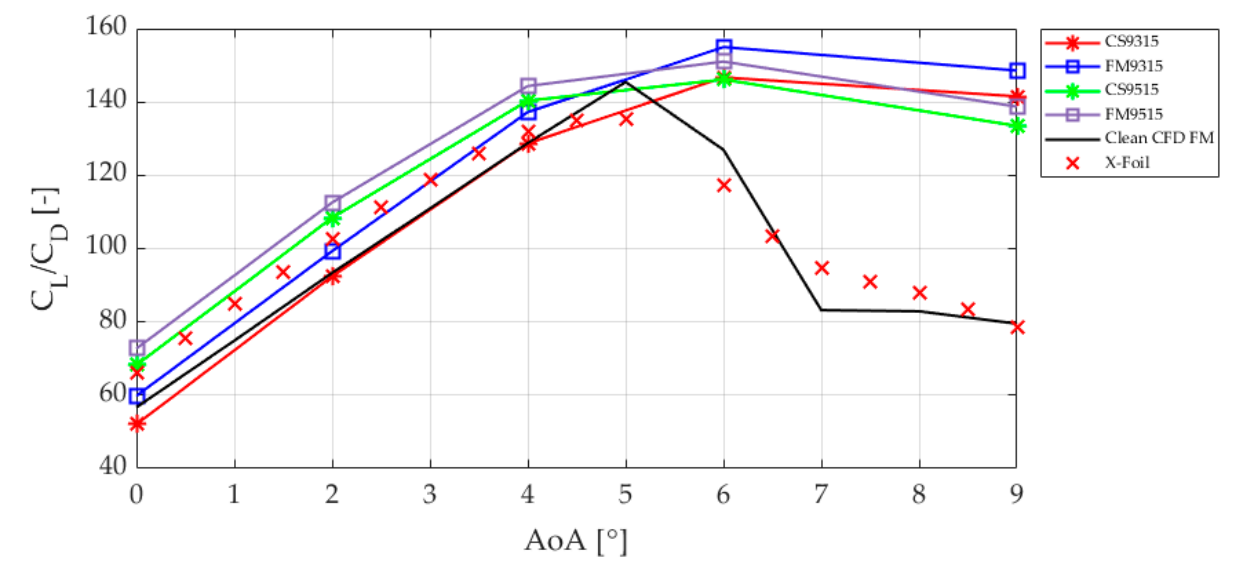

(b)

Figure 4. Cont. 


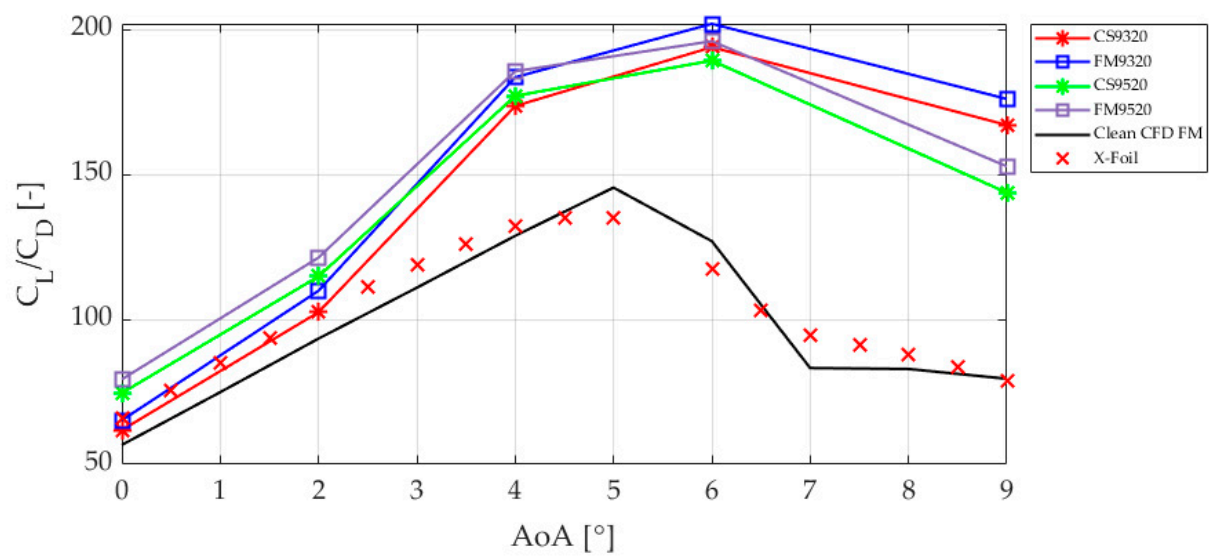

(c)

Figure 4. Aerodynamic performance curves $\left(C_{L} / C_{D}\right.$, lift-to-drag ratio) for different positions on the pressure side of a DU91W(2)250 airfoil: $x=93 \%$ of $c$ and $x=95 \%$ of $c$. Each plot has one MT length (y) assigned: (a) $\mathrm{y}=1.0 \%$ of $\mathrm{c} ;(\mathbf{b}) \mathrm{y}=1.5 \%$ of $\mathrm{c} ;(\mathbf{c}) \mathrm{y}=2.0 \%$ of $\mathrm{c}$. Angles of attack (AoAs) range between 0 and $9^{\circ}$.

As illustrated in Figure 4, the curve formed by the X-foil and the clean fully mesh curve follow a similar pattern. In the same way, the values obtained for the fully mesh model and the cell-set model show approximated ratios. Resulting data show that the position on the pressure side of the airfoil has an effect on the aerodynamic performance: for low AoAs, the performance values result to be higher for an MT located at $95 \%$ of c. By contrast, for AoAs higher than $6^{\circ}$, the airfoil with the MT located at $93 \%$ of $\mathrm{c}$ reaches higher $C_{\mathrm{L}} / \mathrm{C}_{\mathrm{D}}$ values. This effect is enhanced in the CS-FM9315, CS-FM9320, CS-FM9515 and CS-FM9520 cases, where $\mathrm{y}=1.5 \%$ of $\mathrm{c}$ and $\mathrm{y}=2.0 \%$ of c. For the CS-FM9310 and CS-FM9510 cases, the curves tend to be lower at $x=93 \%$ of c, for the whole AoA range, until a $9^{\circ}$ AoA is reached. At that point, the profiles have similar aerodynamic performances.

The evidence suggests that the MT length variations on the pressure side of the airfoil affect more than the distance of the MT from the leading edge in terms of lift-to-drag ratio. Hence, in order to have a clearer description of the MT length variation effect on the aerodynamic performance of the airfoil, the illustrations of Figure 5 have been displayed. Each plot describes eight curves: the previous clean and X-foil curves are represented, with the purpose of following the same references. The remaining curves present the $C_{L} / C_{D}$ ratios for the cell-set and fully mesh models. Magenta, cyan and blue curves with square markers show the fully mesh performances. On the contrary, yellow, green and red curves with asterisk markers describe the results for the cell-set model. There is one position of the MT per plot: $x=93 \%$ of $c(a)$ and $x=95 \%$ of c (b).

Depending on the MT configuration, beneficial or detrimental properties could be added to the airfoil performance. In the previous illustrations of Figure 5, it is clearly presented that the variations in MT length play a significant role in terms of aerodynamic performance. At low values of AoA, MT implementation results to be beneficial in regard to performance, whereas longer MTs describe higher ratios. However, for low AoAs, the MT length variation effect on the $C_{L} / C_{D}$ is not as noticeable as for high AoAs. At $2^{\circ}$, the curves start to diverge. For $y=1.5 \%$ of $\mathrm{c}$ and $\mathrm{y}=2.0 \%$ of $\mathrm{c}$, the performance values are enhanced with MT implementation, the curve of $y=2.0 \%$ of the chord length being the higher one of both of them. Nevertheless, after diverging at AoA $=2^{\circ}$, an MT with $y=1.0 \%$ of clength describes lower values than the clean profile. For this particular case, the profile starts to perform at increased ratios for AoAs higher than $6^{\circ}$. 


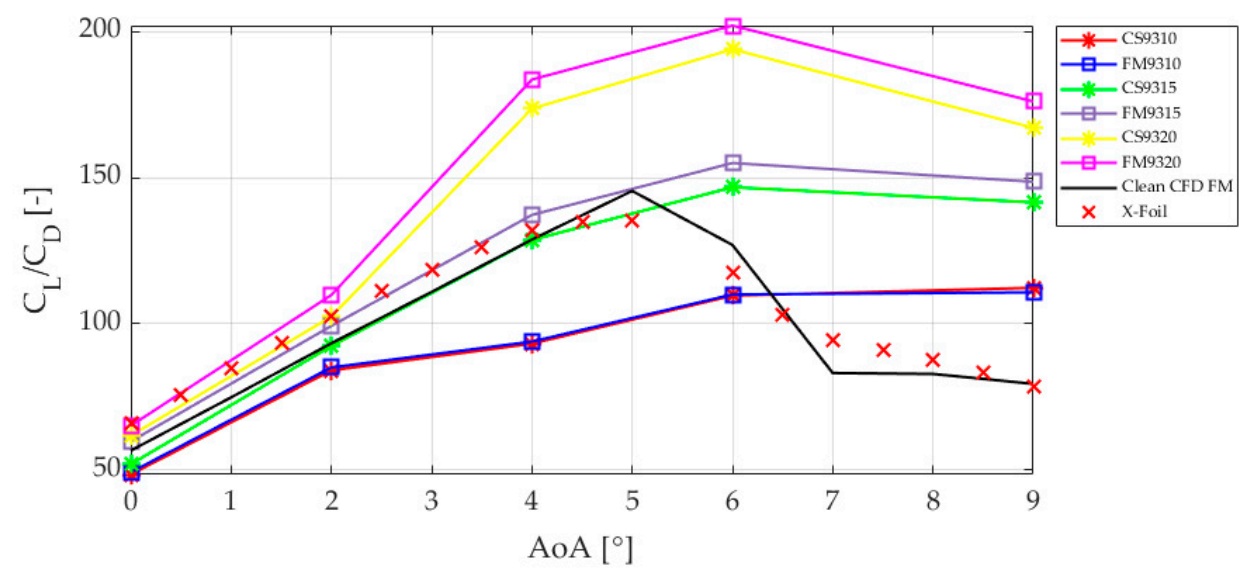

(a)

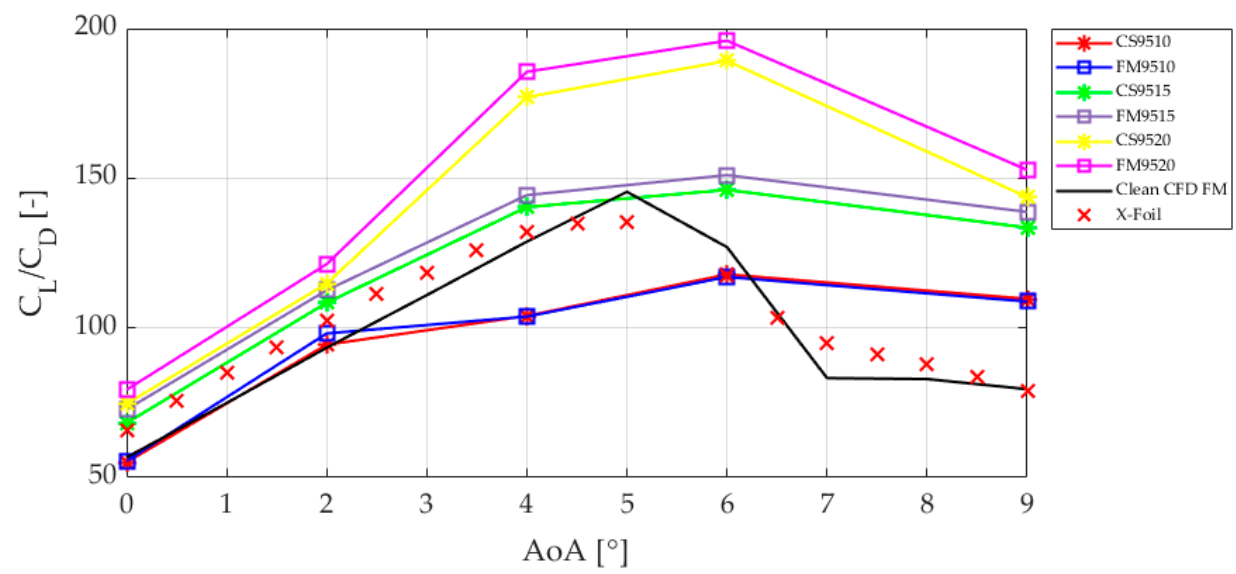

(b)

Figure 5. Aerodynamic performance curves $\left(C_{L} / C_{D}\right.$, lift-to-drag ratio) for different $M T$ lengths implemented on a DU91W(2)250 airfoil: (a) location of the MT at $x=93 \%$ of $c$ and (b) location of the MT at $x=95 \%$ of $c$. AoAs range between 0 and $9^{\circ}$.

After examining the curves, it can be concluded that CS-FM9320 is a suitable and optimum configuration among all the cases studied on this manuscript, closely followed by the CS-FM9520 configuration as the differences in $x[\% c]$ position imply minimal variations in the aerodynamic performance.

\subsection{Error Calculations}

With the aim of obtaining quantitative results for the cell-set model efficiency on an MT application, the relative error for each scenario was determined. Error calculations were performed by comparing the performance results obtained with the cell-set model to the ones obtained with fully mesh simulations. First of all, in order to visualize the errors generated by the cell-set model for each MT configuration, at different AoAs, all the scenes were analyzed case by case as it is illustrated in Figure 6. As previously presented in Section 3.1, aerodynamic performances have been represented for each MT configuration ( $x=93 \%$ of $c$ and $x=95 \%$ of $c$ ). The MT lengths have been designated from $y=1.0 \%$ of $c$ to $y=2.0 \%$ of c. Each plot of Figure 6 displays five different curves: the black continuous line is the constant $C_{L} / C_{D}$ ratio for a clean DU91W(2)250 airfoil without any flow control device implemented. Blue and cyan lines with square markers represent the values obtained for the fully mesh model for $x=93 \%$ of $c$ and $x$ $=95 \%$ of $\mathrm{c}$, respectively. By contrast, red and yellow lines with asterisk markers show the calculations based on the cell-set model. 

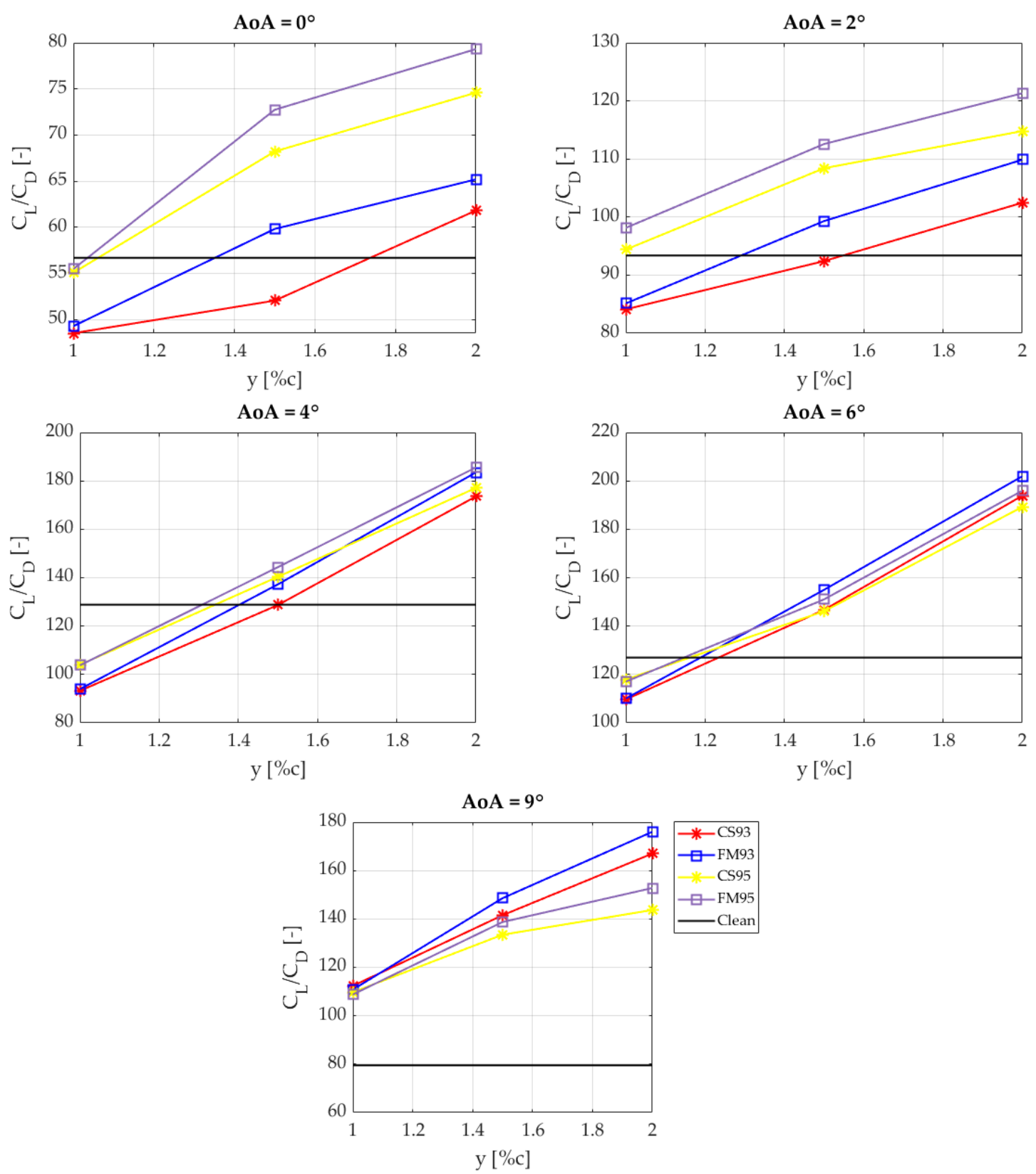

Figure 6. MT configuration cases. Each plot shows the effects of MT length variation on the $C_{L} / C_{D}$ lift-to-drag ratio. A single AoA per plot is represented. AoAs range between 0 and $9^{\circ}$.

Figure 6 represents the error of the cell-set model by taking as a reference the fully mesh one. These relative errors have been calculated by operating with the following formulae: Equation (3) was used to determine the relative error per case. This formula compares the minimum $\left(\min \left(C_{L} / C_{D}\right)\right)$ and maximum $\left(\max \left(C_{L} / C_{D}\right)\right)$ lift-to-drag ratio values between both fully mesh and cell-set models and the result is presented as an error percentage. For some cases, the maximum value is reached with the cell-set model, and for other cases, with the fully mesh model. Moreover, the average relative error values per MT configuration were determined by Equation (4). Subsequently, the global relative error value was calculated by means of Equation (5). All the errors are represented in Table 2. The maximum relative error was reached at a $0^{\circ}$ AoA with the CS9315 configuration with an $\mathrm{e}_{\max }[\%]=7.332 \%$ value. The global relative error value corresponds to $\mathrm{e}_{g}[\%]=3.784 \%$. In the study by Ballesteros-Coll et al. [24], the cell-set model reached a global relative error value of $1.13 \%$. Therefore, it is considered 
that the cell-set model is accurate enough for its application in other scenarios, for the construction of small flow control devices.

$$
\begin{gathered}
\mathrm{e}_{r_{i}}[\%]=\left(1-\frac{\min \left(\frac{C_{L_{i}}}{C_{D_{i}}}\right)}{\max \left(\frac{C_{L_{i}}}{C_{D_{i}}}\right)}\right) \cdot 100 \\
\mathrm{e}_{a v g_{j}}[\%]=\frac{\sum_{i=1}^{N=5} e_{r_{i}}}{N} \\
\mathrm{e}_{g}[\%]=\frac{\sum_{j=1}^{N=6} e_{a v g_{j}}}{N}
\end{gathered}
$$

Table 2. Relative error (\%) per MT configuration case. Average errors are shown in the last row.

\begin{tabular}{ccccccc}
\hline & \multicolumn{7}{c}{ MT Case } \\
\hline AoA $\left.^{(}{ }^{\circ}\right)$ & $\mathbf{9 3 1 0}$ & $\mathbf{9 3 1 5}$ & $\mathbf{9 3 2 0}$ & $\mathbf{9 5 1 0}$ & $\mathbf{9 5 1 5}$ & $\mathbf{9 5 2 0}$ \\
\hline 0 & 1.562 & 7.332 & 5.173 & 0.728 & 6.213 & 5.953 \\
2 & 1.188 & 6.939 & 6.741 & 3.813 & 3.699 & 5.371 \\
4 & 0.748 & 6.231 & 5.412 & 0.211 & 2.762 & 4.568 \\
6 & 0.351 & 5.343 & 3.996 & 0.724 & 3.250 & 3.422 \\
9 & 1.378 & 4.741 & 5.115 & 0.822 & 3.782 & 5.946 \\
$\mathbf{e}_{\boldsymbol{a v g}}(\%)$ & 1.045 & 7.247 & 5.288 & 1.260 & 3.941 & 5.052 \\
\hline
\end{tabular}

\subsection{Qualitative Comparison between Cell-Set and Fully Mesh Models}

In this section, a qualitative comparison between the fully mesh and the cell-set models is carried out. The images presented in Figure 7 show scalar scenes enlarged on the trailing edge area of the DU91W(2)250 airfoil with a CS9320 and a FM9320 MT implemented. Two snapshots have been presented for each AoA that has been studied: the cell-set model is on the left part and the fully mesh model is on the right part.

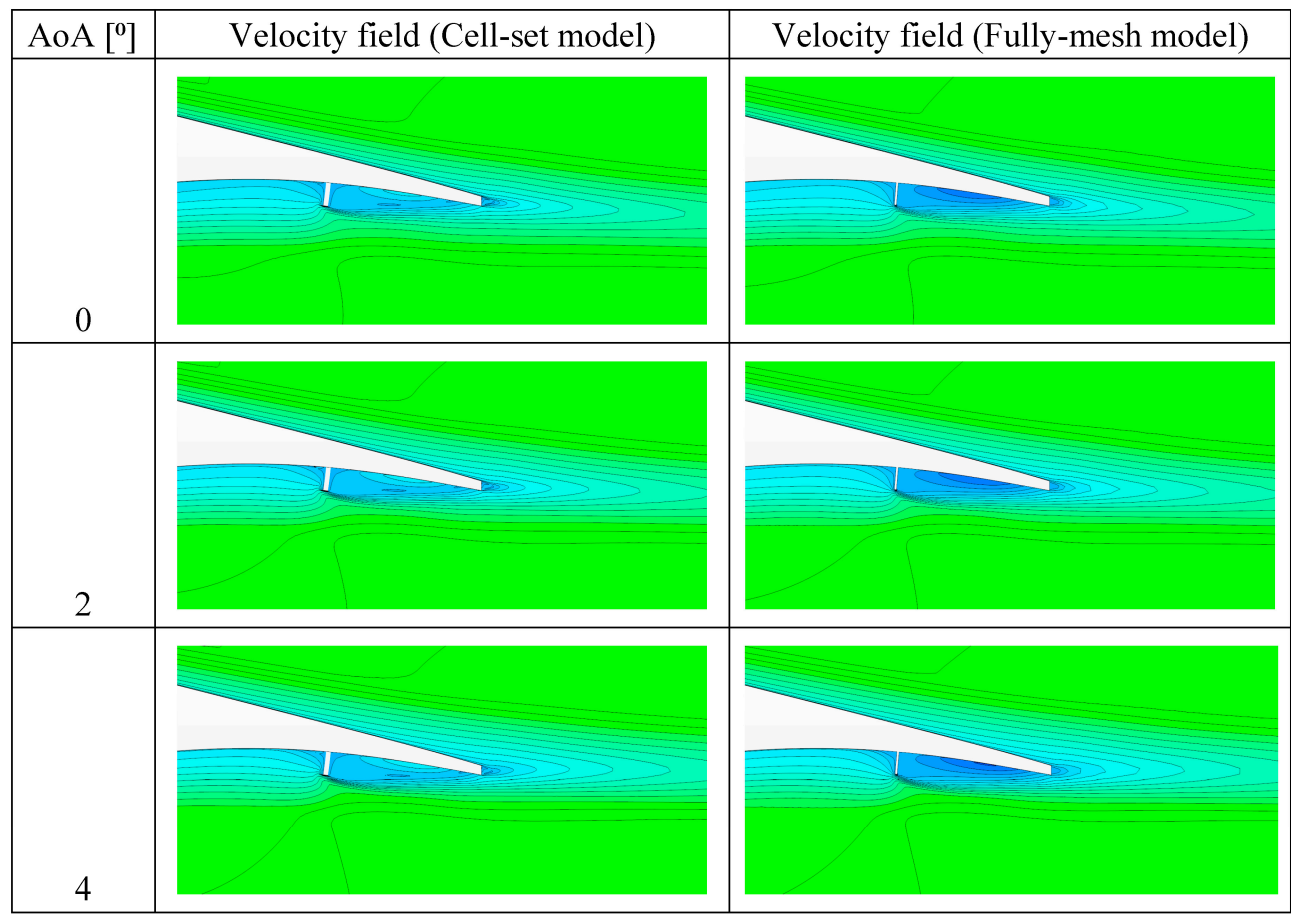

Figure 7. Cont. 


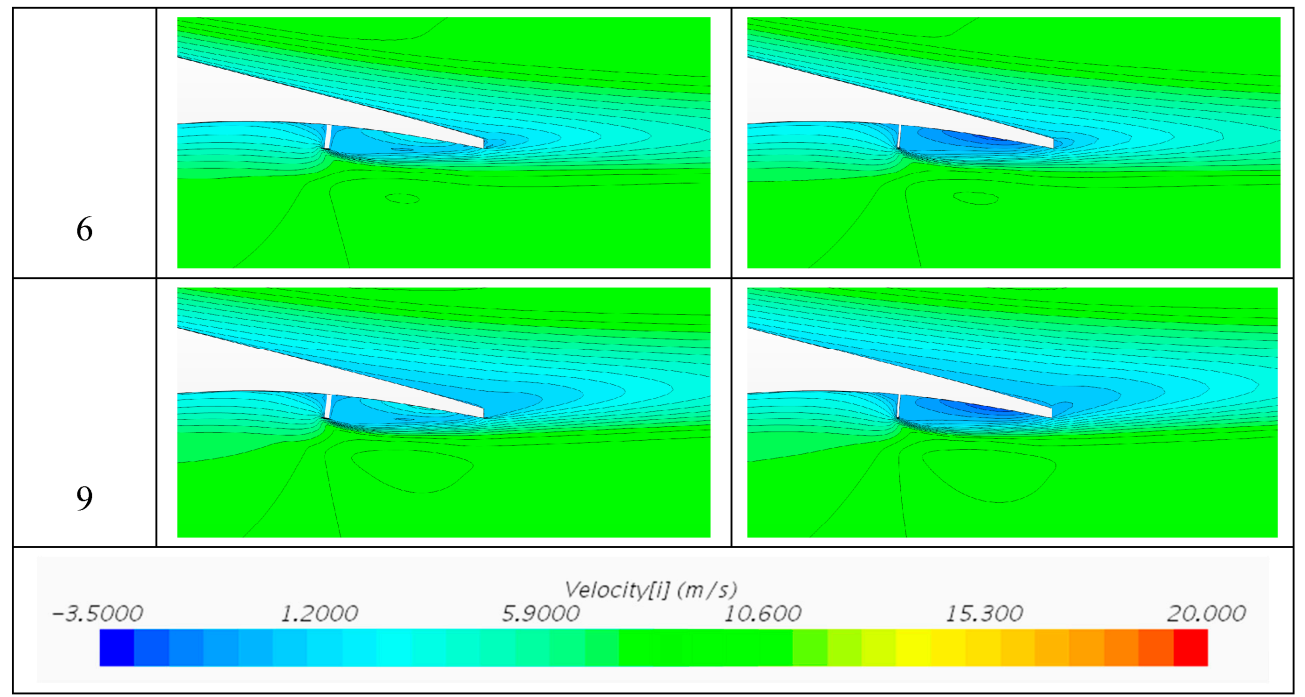

Figure 7. Qualitative comparison of velocity scalar field of the cell-set model and fully mesh model for MT implementation on a DU91W(2)250 airfoil. MT9320 configuration: $x$ [\%c] = 93\%; y [\%c] = 2.0\%.

The correlation between illustrations is noticeable as the geometries created by the cell sets are significantly approximated to the fully mesh geometries. This factor contributes to a similar velocity field around the MT area and in the wake. Additionally, from 0 to $9^{\circ}$, different stream wakes generated by the change in the AoA are clearly represented in both models.

A comparison of pressure distribution was carried out by means of pressure coefficient $(\mathrm{cp})$ values of the DU91W(2)250 airfoil surface. The CS-FM-9320 configuration ( $x=93 \% ; y=2.0 \%$ of $c)$ was selected as it resulted to be the one with the highest aerodynamic performance. Figure 8 represents the $c p$ values for the mentioned case in the whole AoA range studied, for the fully mesh model and for the cell-set model. A continuous black line has been sketched in order to represent the airfoil dimensions. Positive gaps of $\mathrm{cp}$ are generated on the MT position and the aft loading is substantially enhanced on the MT area of the profile.
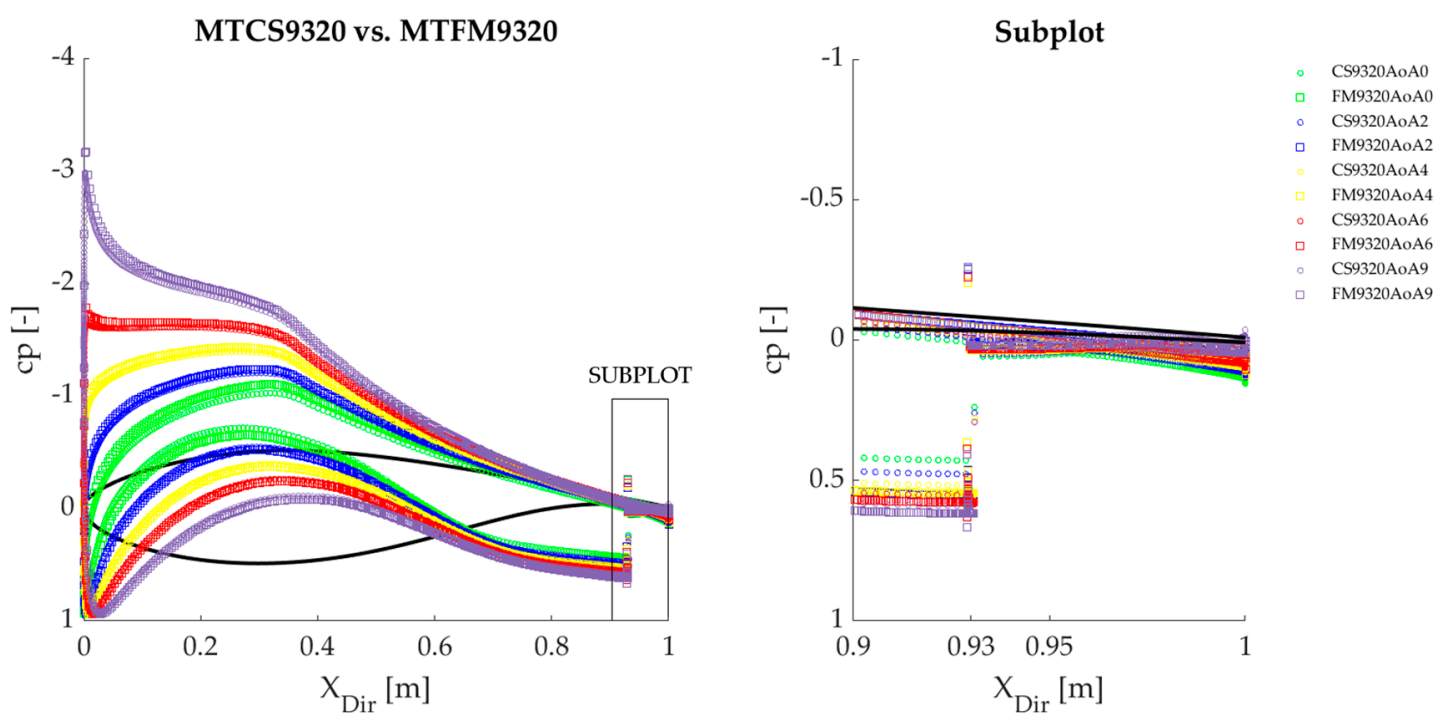

Figure 8. Pressure distribution of the DU91W(2)250_MTCS9320 and DU91W(2)250_MTFM9320 cases represented with the pressure coefficient $(\mathrm{cp})$ at $\mathrm{AoA}=0^{\circ}, 2^{\circ}, 4^{\circ}, 6^{\circ}$ and $9^{\circ}$. The subplot shows an enlarged view of the MT area. 
Different pressure levels show that the pressure drops between suction and pressure sides of the airfoil are enhanced for the fully mesh model in comparison with the cell-set model. This effect could be related to the more noticeable velocity field behind the MT in the fully-mesh (FM) cases; see right column of Figure 7.

The right side of Figure 8 illustrates an enhanced view of the pressure distribution in the MT region. Note that the mesh resolution is significantly smaller than the scale shown in the plot of Figure 8, making the error generated by mesh resolution almost unnoticeable. It can be barely noticed in the subplot where the pressure coefficient values for the cell-set model and fully mesh model are not aligned, as a consequence of the accuracy given by the cell-set.

\section{Conclusions}

In the current work, numerical simulations were carried out in order to study the cell-set model's performance against a fully mesh model for MT implementation on a DU91W(2)250 airfoil. The cell-set model is an adaptable and versatile method to apply when the generation of new and small geometries into a computational domain is demanded. Additionally, no re-meshing processes are required in order to apply the model as the cells are split from the fluid region of the mesh, which is already generated. Consequently, the cell-set model saves mesh calculation times when a geometry has to be added or changed.

Firstly, it was determined that the numerical simulations based on the cell-set model and the fully mesh model formed similar patterns in terms of aerodynamic performance analysis. A global relative error value of $\mathrm{e}_{g}[\%]=3.784 \%$ was reached and a maximum relative error value of $\mathrm{e}_{\max }[\%]=7.332 \%$ was calculated. Considering that the global relative error was significantly low, it can be concluded that the cell-set model is competent for the implementation of an MT in other scenarios. Furthermore, it has been also concluded that generally, when the construction of cells requires a high amount of structured elements, the error generated by the cell-set model tends to be increased.

Secondly, it was observed that the MT position changes along the pressure side of a DU91W(2)250 airfoil do not affect to the aerodynamic performance of the airfoil as much as the variation in the MT length. This factor contributed to a deeper analysis of the effects of MT length variations. Resulting data showed that the optimum MT configuration was reached with a CS-FM9320 configuration, where $x=93 \%$ of $c$ (MT position from the airfoil leading edge) and $y=2.0 \%$ of c (MT length). The CS-FM9320 was closely followed by the CS-FM9520, as the MT position change did not have as much of an effect as the MT length.

Once quantitative evidence of the cell-set performance was obtained, a qualitative analysis was carried out wherein the effects produced on the velocity field by an MT implementation were displayed. Similar results were determined for both models: cell-set and fully mesh. These equally represented the effect of MT implementation since both showed similar wake shapes. In terms of pressure distribution, similar behavior has been observed in both models, with the fully mesh model being the one with the more noticeable pressure drop.

This cell-set based tool could be very helpful in order to perform successful parametric and optimization studies $w$ here a high amount of simulations is required.

Author Contributions: A.B.-C., U.F.-G. and E.Z. formulated and performed the numerical simulations; A.B.-C., U.F.-G., I.A. and J.A.R.-H. studied the results and provided effectual guidelines for the manuscript preparation. All authors have read and agreed to the published version of the manuscript.

Funding: The authors appreciate the support of the government of the Basque Country and the University of the Basque Country UPV/EHU through SAIOTEK (S-PE11UN112), EHU12/26, Grant N. ELKARTEK 20/71 and ELKARTEK 20/78 research programs.

Acknowledgments: The authors are grateful for the support provided by the SGIker of UPV/EHU. This research was developed under the frame of the Joint Research Laboratory on Offshore Renewable Energy (JRL-ORE).

Conflicts of Interest: The authors declare no conflict of interest. 


\section{Nomenclature}

$\begin{array}{lll} & \text { Definition } & \text { Unit } \\ \text { CFD } & \text { Computational fluid dynamics } & - \\ \mathrm{MT} & \text { Microtab } & - \\ \mathrm{GF} & \text { Gurney Flap } & - \\ \mathrm{VG} & \text { Vortex generator } & - \\ \rho & \text { Local density } & \mathrm{kg} / \mathrm{m}^{3} \\ \mu & \text { Dynamic viscosity } & \mathrm{Pa} \cdot \mathrm{s} \\ \mathrm{AoA} & \text { Angle of attack } & \mathrm{deg} \\ \mathrm{c} & \text { Airfoil chord length } & \mathrm{m} \\ \mathrm{RANS} & \text { Reynolds-Averaged Navier-Stokes } & - \\ \mathrm{SST} & \text { Shear stress transport } & - \\ \mathrm{ANN} & \text { Artificial neural network } & - \\ \mathrm{NREL} & \text { National Renewable Energy Laboratory } & - \\ \mathrm{POD} & \text { Proper orthogonal decomposition } & - \\ \mathrm{e}_{r_{i}} & \text { Relative error } & \% \\ \mathrm{e}_{a v g} & \text { Average relative error } & \% \\ \mathrm{e}_{\text {max }} & \text { Maximum relative error } & \% \\ \mathrm{e}_{g} & \text { Global relative error } & \% \\ \mathrm{C}_{\mathrm{L}} & \text { Lift coefficient } & - \\ \mathrm{C}_{\mathrm{D}} & \text { Drag coefficient } & - \\ \mathrm{CP}_{\mathrm{P}} & \text { Pressure coefficient } & - \\ \mathrm{Re}_{V_{\text {rel }}} & \text { Reynolds number } & - \\ & \text { Relative wind velocity } & \mathrm{m} / \mathrm{s}\end{array}$

\section{References}

1. Howell, R.; Qin, N.; Edwards, J.; Durrani, N. Wind tunnel and numerical study of a small vertical axis wind turbine. Renew. Energy 2010, 35, 412-422. [CrossRef]

2. Vermeer, L.J.; Sørensen, J.N.; Crespo, A. Wind turbine wake aerodynamics. Prog. Aerosp. Sci. 2003, 39, 467-510. [CrossRef]

3. Aramendia Iradi, I.; Fernandez Gamiz, U.; Sancho Saiz, J.; Zulueta Guerrero, E. State of the art of active and passive flow control devices for wind turbines. DYNA Ing. E Ind. 2016, 91, 512-516. [CrossRef]

4. Aramendia, I.; Fernandez-Gamiz, U.; Ramos-Hernanz, J.A.; Sancho, J.; Lopez-Guede, J.M.; Zulueta, E. Flow control devices for wind turbines. In Energy Harvesting and Energy Efficiency; Bizon, N., Mahdavi Tabatabaei, N., Blaabjerg, F., Kurt, E., Eds.; Lecture Notes in Energy; Springer International Publishing: Cham, Switzerland, 2017; Volume 37, pp. 629-655. ISBN 978-3-319-49874-4.

5. Velte, C.M.; Hansen, M.O.L. Investigation of flow behind vortex generators by stereo particle image velocimetry on a thick airfoil near stall. Wind Energy 2013, 16, 775-785. [CrossRef]

6. Godard, G.; Stanislas, M. Control of a decelerating boundary layer. Part 1: Optimization of passive vortex generators. Aerosp. Sci. Technol. 2006, 10, 181-191. [CrossRef]

7. Gao, L.; Zhang, H.; Liu, Y.; Han, S. Effects of vortex generators on a blunt trailing-edge airfoil for wind turbines. Renew. Energy 2015, 76, 303-311. [CrossRef]

8. Timmer, W.A.; van Rooij, R. Summary of the Delft University wind turbine dedicated airfoils. J. Sol. Energy Eng. 2003, 125, 488-496. [CrossRef]

9. Timmer, W.A.; Schaffarczyk, A.P. The effect of roughness at high Reynolds numbers on the performance of aerofoil DU 97-W-300Mod. Wind Energy 2004, 7, 295-307. [CrossRef]

10. Martínez-Filgueira, P.; Fernandez-Gamiz, U.; Zulueta, E.; Errasti, I.; Fernandez-Gauna, B. Parametric study of low-profile vortex generators. Int. J. Hydrog. Energy 2017, 42, 17700-17712. [CrossRef]

11. Lin, J.C. Review of research on low-profile vortex generators to control boundary-layer separation. Prog. Aerosp. Sci. 2002, 38, 389-420. [CrossRef]

12. Kumar, P.M.; Samad, A. Introducing Gurney flap to Wells turbine blade and performance analysis with OpenFOAM. Ocean Eng. 2019, 187, 106212. [CrossRef] 
13. Alber, J.; Pechlivanoglou, G.; Paschereit, C.O.; Twele, J.; Weinzierl, G. Parametric investigation of gurney flaps for the use on wind turbine blades. In Proceedings of the Volume 9: Oil and Gas Applications; Supercritical CO2 Power Cycles; Wind Energy; American Society of Mechanical Engineers, Charlotte, NC, USA, 26-30 June 2017; p. V009T49A015.

14. Aramendia, I.; Fernandez-Gamiz, U.; Zulueta, E.; Saenz-Aguirre, A.; Teso-Fz-Betoño, D. Parametric study of a gurney flap implementation in a DU91W(2)250 airfoil. Energies 2019, 12, 294. [CrossRef]

15. Zhu, B.; Huang, Y.; Zhang, Y. Energy harvesting properties of a flapping wing with an adaptive Gurney flap. Energy 2018, 152, 119-128. [CrossRef]

16. Saenz-Aguirre, A.; Fernandez-Gamiz, U.; Zulueta, E.; Ulazia, A.; Martinez-Rico, J. Optimal wind turbine operation by artificial neural network-based active gurney flap flow control. Sustainability 2019, 11, 2809. [CrossRef]

17. Gruschwitz, E.; Schrenk, O. A Simple Method for Increasing the Lift of Airplane Wings by Means of Flaps; NASA: Washington, DC, USA, 1933.

18. Van Dam, C.P.; Nakafuji, D.Y.; Bauer, C.; Standish, K.; Chao, D. Computational design and analysis of a microtab-based aerodynamic load control system for lifting surfaces. In Proceedings of the MEMS Components and Applications for Industry, Automobiles, Aerospace, and Communication II, San Jose, CA, USA, 25-31 January 2003; Volume 4981.

19. Baker, J.P.; Standish, K.J.; van Dam, C.P. Two-dimensional wind tunnel and computational investigation of a microtab modified airfoil. J. Aircr. 2007, 44, 563-572. [CrossRef]

20. Ebrahimi, A.; Movahhedi, M. Wind turbine power improvement utilizing passive flow control with microtab. Energy 2018, 150, 575-582. [CrossRef]

21. Cooperman, A.M.; Chow, R.; van Dam, C.P. Active load control of a wind turbine airfoil using microtabs. J. Aircr. 2013, 50, 1150-1158. [CrossRef]

22. Johnson, S.J.; Baker, J.P.; van Dam, C.P.; Berg, D. An overview of active load control techniques for wind turbines with an emphasis on microtabs. Wind Energy 2010, 13, 239-253. [CrossRef]

23. Sanderse, B.; Pijl, S.P.; Koren, B. Review of computational fluid dynamics for wind turbine wake aerodynamics: Review of CFD for wind turbine wake aerodynamics. Wind Energy 2011, 14, 799-819. [CrossRef]

24. Ballesteros-Coll, A.; Fernandez-Gamiz, U.; Aramendia, I.; Zulueta, E.; Lopez-Guede, J.M. Computational methods for modelling and optimization of flow control devices. Energies 2020, 13, 3710. [CrossRef]

25. Jirasek, A. Vortex-generator model and its application to flow control. J. Aircr. 2005, 42, 1486-1491. [CrossRef]

26. Errasti, I.; Fernández-Gamiz, U.; Martínez-Filgueira, P.; Blanco, J. Source term modelling of vane-type vortex generators under adverse pressure gradient in OpenFOAM. Energies 2019, 12, 605. [CrossRef]

27. Chillon, S.; Uriarte-Uriarte, A.; Aramendia, I.; Martínez-Filgueira, P.; Fernandez-Gamiz, U.; Ibarra-Udaeta, I. jBAY modeling of vane-type vortex generators and study on airfoil aerodynamic performance. Energies 2020, 13, 2423. [CrossRef]

28. Fernandez, U.; Réthoré, P.-E.; Sørensen, N.N.; Velte, C.M.; Zahle, F.; Egusquiza, E. Comparison of four different models of vortex generators. In Proceedings of the EWEA 2012-European Wind Energy Conference \& Exhibition; European Wind Energy Association (EWEA), Copenhagen, Denmark, 16-19 April 2012.

29. Fernandez-Gamiz, U.; Gomez-Mármol, M.; Chacón-Rebollo, T. Computational modeling of gurney flaps and microtabs by POD method. Energies 2018, 11, 2091. [CrossRef]

30. Jonkman, J.; Butterfield, S.; Musial, W.; Scott, G. Definition of a 5-MW Reference Wind Turbine for Offshore System Development; Technical Report No. NREL/TP-500-38060; National Renewable Energy Lab.: Golden, CO, USA, 2009; p. 7.

31. Siemens Star CCM+ Version 14.02.012. Available online: https://www.plm.automation.siemens.com/global/ en/ (accessed on 3 February 2020).

32. Sørensen, N.N.; Mendez, B.; Munoz, A.; Sieros, G.; Jost, E.; Lutz, T.; Papadakis, G.; Voutsinas, S.; Barakos, G.N.; Colonia, S.; et al. CFD code comparison for 2D airfoil flows. J. Phys. Conf. Ser. 2016, 753, 082019. [CrossRef]

33. Fernandez-Gamiz, U.; Zulueta, E.; Boyano, A.; Ramos-Hernanz, J.; Lopez-Guede, J. Microtab design and implementation on a 5 MW wind turbine. Appl. Sci. 2017, 7, 536. [CrossRef]

34. Thompson, J.F.; Warsi, Z.U.A.; Mastin, C.W. Numerical Grid Generation: Foundations and Applications; Elsevier Science (North-Holland Publishing Co.): New York, NY, USA, 1985; ISBN 978-0-444-00985-2.

35. Vinokur, M. On one-dimensional stretching functions for finite-difference calculations. J. Comput. Phys. 1983, 50, 215-234. [CrossRef] 
36. Menter, F.R. Two-equation eddy-viscosity turbulence models for engineering applications. AIAA J. 1994, 32, 1598-1605. [CrossRef]

37. Kral, L.D. Recent experience with different turbulence models applied to the calculation of flow over aircraft components. Prog. Aerosp. Sci. 1998, 34, 481-541. [CrossRef]

38. Reck, M. Computational Fluid Dynamics, with Detached Eddy Simulation and the Immersed Boundary Technique, Applied to Oscillating Airfoils and Vortex Generators. Ph.D. Thesis, Technical University of Denmark, Lyngby, Denmark, 28 September 2005.

39. Kooijman, H.J.T.; Lindenburg, C.; Winkelaar, D.; Hooft, E.L.V.D. Aero-Elastic Modelling of the DOWEC 6 MWre-Design in PHATAS; DOWEC-F1W2-HJK-01-046/9; Tech. Rep. ECN-CX-01-135, DOWEC 10046_009; Energy Research Center of the Netherlands: Petten, The Netherlands, 2003.

40. Lindenburg, C. Aeroelastic Modelling of the LMH64-5 Blade; DOWEC-02-KL-083/0, DOWEC 10083_001; Energy Research Center of the Netherlands: Petten, The Netherlands, 2002.

Publisher's Note: MDPI stays neutral with regard to jurisdictional claims in published maps and institutional affiliations.

(C) 2020 by the authors. Licensee MDPI, Basel, Switzerland. This article is an open access article distributed under the terms and conditions of the Creative Commons Attribution (CC BY) license (http://creativecommons.org/licenses/by/4.0/). 